\title{
Que interdisciplinaridade a BNCC oferece à Filosofia? Aproximações à língua portuguesa
}

\author{
What sort of interdisciplinarity does the BNCC offer to philosophy? \\ Some approaches to the portuguese language
}

\author{
Thiago Gruner Conceição \\ Graduando na Universidade Federal do Rio Grande do Sul, Porto Alegre, Rio Grande do Sul, Brasil. \\ thiagogruner@gmail.com \\ ORCID: http://orcid.org/0000-0002-0247-8054
}

Recebido em 05 de maio de 2019

Aprovado em 08 de outubro de 2019

Publicado em 07 de janeiro de 2020

RESUMO: Este artigo analisa a quarta e definitiva versão da Base Nacional Comum Curricular, de 2018, à luz da já antiga promessa de tornar a educação básica brasileira mais interdisciplinar. Mais especificamente, a pergunta que guia essa análise, e a que o artigo pretende responder é: que indicações e possibilidades de um trabalho interdisciplinar a Base oferece a professores e estudantes de Filosofia? Parte-se do pressuposto de que a Base, ainda que trabalhe com áreas de conhecimento, contém em suas competências e habilidades a presença indireta das disciplinas mais tradicionais. É assim possível identificar nas tais áreas de conhecimento aquelas habilidades que mais são afins à disciplina em questão. Ao mesmo tempo, também é possível encontrar cruzamentos entre as habilidades dessas disciplinas (no presente caso, Filosofia e Língua Portuguesa), levando em conta seus objetos de conhecimento ou seus processos cognitivos. O resultado é uma lista não-exaustiva de quatro relações interdisciplinares possíveis entre Filosofia e Língua Portuguesa, a partir da BNCC, passando por temas como ética e epistemologia, instrumentos como análise e composição de argumentos, até alguns aspectos socioafetivos. Ao fim, tais relações interdisciplinares são ilustradas, na prática, sob a forma de uma proposta de sequência didática. Palavras-chave: BNCC; Currículo; Interdisciplinaridade; Filosofia; Língua Portuguesa.

ABSTRACT: This paper analyses the fourth and final version of the National Common Curricular Base (BNCC, 2018), considering the not so recent efforts to make the Brazilian basic education (K12) more interdisciplinary. More specifically, the question that guides this analysis, and which the article intends to answer, is: what sort of a possible interdisciplinary work does the Base offer to Philosophy students and teachers? The paper assumes that the Base, although mostly dealing with "knowledge areas", indirectly contains in its skills and competencies the presence of the more traditional school subjects. It is thus possible to identify in those knowledge areas the skills that are most related to the subject at issue. At the same time, by taking into account objects of knowledge and cognitive processes, one can find crossings between the skills of these subjects (in the present case, Philosophy and Portuguese Language). The result is a non-exhaustive list of four possible interdisciplinary relations between Philosophy and Portuguese Language, drawn from the BNCC, approaching themes such as ethics and epistemo- 
logy, instruments such as arguments analysis and composition, as well as social and affective aspects. Lastly, the interdisciplinary relations are illustrated in the form of a small syllabus proposal.

Keywords: BNCC; Curriculum; Interdisciplinarity; Philosophy; Portuguese.

\section{Introdução}

Há pelo menos duas décadas documentos oficiais brasileiros ${ }^{1}$ tratam da promessa de uma educação interdisciplinar (isto é: que aproxime, no ensino e na aprendizagem, duas ou mais disciplinas, buscando um conhecimento mais "orgânico"2).

Mais recentemente, as três primeiras versões da Base Nacional Comum Curricular (BNCC), de 2015, 2016 e 2018, também seguiram nessa direção³. Por isso proponho ler a quarta e definitiva versão da BNCC, também de 2018, à luz desses esforços ${ }^{4}$.

De fato, a Base aponta para a necessidade de "contextualizar os conteúdos dos componentes curriculares, identificando estratégias para (...) conectá-los e torná-los significativos" 5 .Ao lado dos currículos, ela propõe-se ser um instrumento que permita às escolas

decidir sobre formas de organização interdisciplinar dos componentes curriculares e fortalecer a competência pedagógica das equipes escolares para adotar estratégias mais dinâmicas, interativas e colaborativas em relação à gestão do ensino e da aprendizagem. (BRASIL, 2018, p. 16.)

Sendo assim, pergunto: que indicações e possibilidades de um trabalho interdisciplinar a Base oferece a professores e estudantes de Filosofia?

Uma resposta a essa pergunta passa por seu texto, é claro. E uma vez que a Base é documento extenso, reduzo, por uma questão simplesmente prática, minha análise às disciplinas de Português e Filosofia no Ensino Médio. De todo modo, creio que esse recorte permite vislumbrar, pelo exemplo, o trabalho de aproximar a Filosofia das demais disciplinas, bem como estas entre si. E aqui cabe lembrar: a Base do Ensino Médio, na sua maior parte, não trata diretamente de disciplinas (à exceção de Matemática e Língua Portuguesa), mas de áreas do conhecimento ${ }^{6}$. Mesmo assim, podemos entender que há, sim, a presença indireta de disciplinas na BNCC pelo fato de que a interdisciplinaridade (como o próprio nome indica) pressupõe a existência de disciplinas - e não sua eliminação, como pode-se pensar.

Considerando que um documento como a Base pretende abstrair quase todas as disciplinas em meio a grandes áreas multidisciplinares de conhecimento, busquei avistar a presença da Filosofia na área de Ciências Humanas e suas Tecnologias (seu locus tradicional), olhando justamente para os elementos que constituem a Base: as competências e habilidades.

Assim, meu objetivo é analisar a quarta versão da BNCC para o Ensino Médio, elaborando uma lista não-exaustiva de possíveis relações interdisciplinares entre as competências e habilidades ${ }^{7}$ de Filosofia e Língua Portuguesa (sem excluir as habilidades da área de Linguagens). Apresentarei quatro dessas relações e, ao final, ilustrarei uma delas com uma proposta de sequência de algumas aulas. 


\section{Possíveis relações}

A Base apresenta a disciplina de Língua Portuguesa no Ensino Médio como encarregada de, entre outras coisas, "promover o desenvolvimento de habilidades relativas ao trato com a informação e a opinião, no que diz respeito à veracidade e à confiabilidade de informações, à adequação, validade e força dos argumentos" (BRASIL, 2018, p. 498). Além de uma proximidade com conceitos importantes da epistemologia, interessa mais para os propósitos deste artigo a proximidade com aquele que é o núcleo duro das competência filosóficas: a argumentação (COSTA, 2003).

A mesma Língua Portuguesa preza pelo domínio da gramaticalidade: o saber compreender e fazer-se compreender pelas regras de uma língua. Aqui, mais uma vez, percebe-se proximidade natural com a Filosofia, pois ainda que não seja condição suficiente para o filosofar, "a competência de interpretação é requerida como condição necessária para a atividade filosófica" (COSTA, 2003, p. 82) - e, acrescento, fazer-se entender sem ambiguidade ou vagueza. Por fim, poder-se-ia apontar a prevalência do texto, em nossa disciplina, como objeto mais tradicional de interpretação, bem como aquele privilegiado para a comunicação de ideias.

É tendo em vista esse entrelaçamento entre competências linguísticas e filosóficas que apresento o que considero ser algumas das relações mais evidentes entre as competências e habilidades de Língua Portuguesa e Filosofia para o Ensino Médio na BNCC.

\section{Relação 1: Habilidades Português 40 e Humanas 501}

Comecemos relacionando uma habilidade de Língua Portuguesa e uma competência das Ciências Humanas:

EM13LP408: Analisar o fenômeno da pós-verdade - discutindo as condições e os mecanismos de disseminação de fake news e também exemplos, causas e consequências desse fenômeno e da prevalência de crenças e opiniões sobre fatos -, de forma a adotar atitude crítica em relação ao fenômeno e desenvolver uma postura flexível que permita rever crenças e opiniões quando fatos apurados as contradisserem. (BRASIL, 2018, p. 521)

EM13CHS501: Compreender os fundamentos da ética em diferentes culturas, tempos e espaços, identificando processos que contribuem para a formação de sujeitos éticos que valorizem a liberdade, a cooperação, a autonomia, o empreendedorismo, a convivência democrática e a solidariedade. (BRASIL, 2018, p. 577)

A discussão do fenômeno das fake news demanda naturalmente respostas à questão do compromisso ético com a verdade: "Temos o dever de falar a verdade? - por quê? Sempre ou em alguns casos?". Em suma, pergunta-se aos alunos se a verdade deve ser um valor ou se pode ser instrumentalizada, quiçá ignorada. Tais questionamentos ganham 
maior importância se adentramos o terreno da ética aplicada e nos perguntamos pela conduta ética do profissional de jornalismo, com o qual muitos alunos entram em contato diariamente. Abre-se espaço para investigar o fundamento da verdade (ela funcionaria à moda jornalística, por correspondência?) e se a própria moral teria valor de verdade.

Junto a uma aula de Português que lide com colunas de jornal ou segmentos de opinião, nossa especialidade epistemológica também permite tematizar o próprio conceito de opinião, bem como o da crença. Há ainda oportunidade de investigar a confiabilidade do testemunho em geral, que na sociedade democrática é fundamental para a verificação de informações e a tomada de decisão (voto). Conseguindo fazer isso, o professor valoriza os meios de comunicação responsáveis, ao mesmo tempo que alerta para os perigos da manipulação. Será um trabalho que, como pede a Base, fortalecerá a autonomia e a convivência democrática.

Negar a intersubjetividade da construção de conhecimento na esfera pública teria consequências que podem ser trazidas à sala de aula: será que isso não produziria sujeitos irresponsáveis, egoístas e relativizantes? O que os alunos diriam que aconteceria se cada indivíduo adotasse a sua própria verdade? Tais condutas parecem incompatíveis com a vida democrática, em que se busca sempre que possível o consenso firmado sobre base comum.

Evitando, assim, o império da opinião, desenvolvemos uma postura flexível que permita rever crenças frente à fatos que as contradigam. O que, conforme a Base, seria contribuir para formação de sujeitos éticos que valorizem a liberdade, a autonomia e a democracia.

\section{Relação 2: Português 05 e Habilidades Humanas 103}

Continuemos, relacionando outras duas habilidades:

EM13LP05: Analisar, em textos argumentativos, os posicionamentos assumidos, os movimentos argumentativos (sustentação, refutação/ contra-argumentação e negociação) e os argumentos utilizados para sustentá-los, para avaliar sua força e eficácia, e posicionar-se criticamente diante da questão discutida e/ou dos argumentos utilizados, recorrendo aos mecanismos linguísticos necessários. (BRASIL, 2018, p. 507)

EM13CHS103: Elaborar hipóteses, selecionar evidências e compor argumentos relativos a processos políticos, econômicos, sociais, ambientais, culturais e epistemológicos, com base na sistematização de dados e informações de diversas naturezas (expressões artísticas, textos filosóficos e sociológicos, documentos histórico e geográficos, gráficos, mapas, tabelas, tradições orais, entre outros). (BRASIL, 2018, p. 572)

Essa segunda relação oferece-nos a oportunidade de encarar o argumento como uma moeda de duas faces: em sua composição e em sua análise. Assim como a leitura fortalece a escrita (e vice-versa), a análise argumentativa de que fala EM13LP05 alimenta a atividade de composição argumentativa em EM13CHS103 (que por sua vez 
retroalimenta a primeira). Em outras palavras, identificar premissas e movimentos inferenciais em um texto ajuda o aluno a compor seus próprios argumentos com maior força lógica e clareza. Do mesmo modo, buscar fragilidades no texto alheio com vistas a objeções, ajuda a criar a disposição de antever, no momento da escrita, possíveis críticas.

Se EM13LP05 não faz referência ao modo como avalia-se a força e eficácia de um argumento, EM13CHS103 fornece uma chave para isso: a seleção de evidências qualitativas e quantitativas é a matéria-prima da elaboração de hipóteses acerca de um problema. Por exemplo: quando os alunos perguntarem-se sobre o que determina o significado de uma expressão artística, poderemos apresentar como os argumentos das diferentes posições filosóficas sobre o assunto variam em força; se sobre uma mesma obra forem elaboradas hipóteses idealizadas, sem evidências concretas (intencionalismo hipotético), ou se forem colhidos certos tipos de evidências (declarações do artista, como no intencionalismo clássico, ou conteúdo e forma da obra, como no autonomismo).

\section{Relação 3: Habilidades Linguagens 303, Português 24 e Competência Humanas $n^{\circ} 6$}

Uma outra relação possível dá-se entre as seguintes:

EM13LGG303: Debater questões polêmicas de relevância social, analisando diferentes argumentos e opiniões, para formular, negociar e sustentar posições, frente à análise de perspectivas distintas. (BRASIL, 2018, p. 493)

EM13LP25: Participar de reuniões na escola (conselho de escola e de classe, grêmio livre etc.), agremiações, coletivos ou movimentos, entre outros em debates, assembleias, fóruns de discussão etc., exercitando a escuta atenta, respeito seu turno e tempo de fala, posicionando-se de forma fundamentada, respeitosa e ética diante da apresentação de propostas e defesas de opiniões, usando estratégias linguísticas típicas de negociação de apoio e/ou de consideração do discurso do outro (como solicitar esclarecimento, detalhamento, fazer referência direta ou retomar a fala do outro, parafraseando-a para endossá-la, enfatizá-la, complementá-la ou enfraquecê-la), considerando propostas alternativas e reformulando seu posicionamento, quando for o caso, com vistas ao entendimento e ao bem-comum. (BRASIL, 2018, p. 514)

Competência específica de Ciências Humanas e Sociais $n^{\circ} 6$ : Participar do debate público de forma crítica, respeitando diferentes posições e fazendo escolhas alinhadas ao exercício da cidadania e ao seu projeto de vida, com liberdade, autonomia, consciência crítica e responsabilidade. (BRASIL, 2018, p. 570)

Aqui a competência e as habilidades relacionam-se intimamente para privilegiar menos o aspecto prático-teórico das disciplinas (suas teorias, procedimentos, problemas 
etc.) e mais o aspecto socioafetivo. Com efeito, "ouvir, respeitar e responder as ideias e argumentos alheios", bem como "aceitar que as suas ideias e argumentos sejam discutidos e avaliados pelos outros" é o que Costa (2003, p. 85) chama de "princípios da ética do debate filosófico". Mas não somente: a própria Base (2018, p. 498), na abertura de seu capítulo sobre Língua Portuguesa, prevê "o desenvolvimento de habilidades que possibilitem o trato com o diverso e o debate de ideias".

A importância e riqueza de trabalhar a presente relação é grande: em primeiro, afasta o perigo, apontado por Ronai Rocha (2013), de que o debate da aula de filosofia resvale para o ralo das opiniões. O debate deve ser pautado pelo rigor conceitual e argumentativo, a honestidade intelectual e, mais especificamente, o princípio de caridade (evitando seu oposto, a falácia do espantalho). Essa é inclusive a oportunidade para que o professor apresente à turma a diferença entre os conceitos de oratória, retórica e persuasão - quem sabe através da ancestral contenda entre filósofos e sofistas.

Em segundo lugar, um debate crítico e responsável barra o que podemos chamar de "estética do lacre". É possível que, em sala de aula, os alunos se impressionem com frases de efeito (respondendo "lacrou!"). Ora, cabe ao professor criar um ambiente em que o que impressione não é a aparência de profundidade, mas, sim, a real pertinência da fala do colega.

Mas é claro que a criação de um tal ambiente não pode ferir os sentimentos dos alunos. $O$ que me leva a um terceiro ponto: um debate responsável separa a ideia daquele que a formula - o que, também segundo Rocha (2013, p. 45), é uma dificuldade no caso dos problemas filosóficos, que em sua maioria geram grande envolvimento pessoal. É normal, claro, que durante a adolescência a construção de uma identidade passe pela adoção de crenças e opiniões, mas os alunos devem ter cristalina clareza de que um debate em filosofia (como outros) não pode ser levado para o lado pessoal - e que portanto não se sintam atacados em sua individualidade.

\section{Relação 4: Habilidades Linguagens 102, Português 02 e Humanas 101}

Por fim, mais uma relação possível, dessa vez entre:

EM13LGG102: Analisar visões de mundo, conflitos de interesse, preconceitos e ideologias presentes nos discursos veiculados nas diferentes mídias, ampliando suas as possibilidades de explicação, interpretação e intervenção crítica da/na realidade. (BRASIL, 2018, p. 491)

EM13LP02: Estabelecer relações entre as partes do texto, tanto na produção como na leitura/escuta, considerando a construção composicional e o estilo do gênero, usando/reconhecendo adequadamente elementos e recursos coesivos diversos que contribuam para a coerência, a continuidade do texto e sua progressão temática, e organizando informações, tendo em vista as condições de produção e as relações lógico-discursivas envolvidas (causa/efeito ou consequência; tese/argumentos; problema/solução; definição/exemplos etc.).

(BRASIL, 2018, p. 506) 
A primeira e terceira habilidades apontam na direção de uma interpretação da realidade através de diferentes mídias e linguagens. Essa interpretação será tanto mais facilitada quanto melhor for a organização das informações utilizadas (falas, premissas implícitas, situação contextual, etc.) - coisa que a segunda habilidade preconiza.

A análise cuidadosa do discurso de um governante, por exemplo, pode por um lado revelar premissas implícitas em seus argumentos, expondo um subtexto de preconceitos ou ideologias. Tal procedimento permitiria identificar se o que de fato está sendo defendido (a tese ou conclusão) é implicado pelas premissas - e se a solução oferecida por ele, por exemplo, de fato teria relação com o problema em questão.

Cabe ressaltar o rico espaço de trabalho que essa relação entre três habilidades oferece, sugerindo uma gama de diferentes mídias e linguagens a serem abordadas (lembremos também de EMCHS103, que fala de obras de arte, textos e relatos orais). Sobre todos poderemos fazer filosofia (nossa disciplina é corrosiva, como costuma-se dizer), sem prejuízo do uso de textos tipicamente filosóficos.

\section{Proposta de sequência didática com base na $1^{a}$ relação (Ip40 e chs501)}

As relações interdisciplinares apresentadas, como dito, não pretendem esgotar um documento tão vasto quanto a Base. Da mesma maneira, a proposta de sequência didática a seguir é apenas uma de tantos trabalhos possíveis entre as habilidades que visam fazer analisar a pós-verdade e reconhecer os fundamentos éticos (LP40 e CHS501).

A sequência abaixo foi pensada a partir do que seria a síntese dos objetivos previstos nas duas habilidades (o que chamei de "objetivo geral"). Com isso foi possível desdobrá-la em objetivos específicos e certas estratégias de aprendizagem, que, uma vez mais, não pretendem ser exaustivas. Se o tema ou problema principal dessa sequência servisse de guia condutor para o trabalho de um trimestre de cerca de vinte aulas, a sequência poderia ser confortavelmente executada na íntegra ${ }^{9}$. Acredito que a sequência poderia ser ministrada em qualquer nível do Ensino Médio, dependendo do contexto social e dos pré-requisitos dos alunos em questão. Ela certamente também poderia ser mais ou menos longa.

Por fim, noto o caráter imaginativo da proposta que apresento. Uma sequência real teria o apoio de um currículo específico - pois a Base, como o próprio nome diz, não é instrumento que se valha sozinho.

Tema: Ética da verdade

Problema principal: quais são as consequências éticas e políticas da prevalência de opiniões sobre fatos? 
Tópicos: 1) Opinião, conhecimento e verdade na mídia; 2) Causas, motivos e razões para crer; 3) Imperativo categórico de Kant; 4) O critério pragmático de verdade.

Objetivo geral: Capacitar os alunos a reconhecer e analisar o fenômeno da pós-verdade e das fake news na mídia, bem como da prevalência de opiniões sobre fatos, identificando as consequências éticas sobre uma sociedade que se pretende cooperativa, autônoma e democrática, tomando posição argumentativa frente a elas com o auxílio de teses e conceitos filosóficos consagrados e recursos linguísticos apropriados.

Objetivos específicos: i) Diferenciar expressão de opiniões e veiculação de notícias em diferentes mídias; ii) Identificar limites na pretensão midiática de transmitir a verdade; iii) Compreender a diferença entre conhecimento e informação, avaliando se e como jornalismo, redes sociais e novas mídias podem ser fontes de conhecimento; iv) Distinguir causas, motivos e razões para crer em algo; iv) Compreender, avaliar e posicionar-se frente aos argumentos de Immanuel Kant sobre o dever de se falar a verdade; v) Compreender o critério pragmático de verdade, bem como suas críticas; vi) Posicionar-se frente às consequências da adoção de um critério pragmático de verdade, relacionando-o com a pós-verdade.

Estratégias de ensino: 1) Leitura, em aula, de uma coluna de opinião e de uma reportagem jornalística; e/ou exibição e análise, em aula, de vídeo de opinião (youtubers, comentaristas, etc.) e de reportagem audiovisual (telejornal, documental, etc.); 2) Redação inspirada na estratégia 1, em que se responde à questão "posso saber sozinho se o que leio e assisto é verdadeiro?", utilizando os indicadores linguísticos de premissa, inferência e conclusão; 3) Debate e reflexão coletiva sobre como seria a democracia se não houvesse mídia, jornalismo ou critério de verdade; 4) Exposição do problema "Podemos ter outros interesses que não o da verdade, no momento em que cremos em algo?", seguida de exposição acerca da distinção entre causas, motivos e razões para crer; 5) Exercício de identificação e construção de exemplos em que empregam-se razões (sustentação da verdade) e motivos (interesse nas consequências) para crer em algo; 6) Redação acerca das consequências de se crer em algo por interesse, e não por razões, utilizando os indicadores linguísticos de premissa, inferência e conclusão; 7) Exposição do problema "Devemos sempre falar a verdade?", seguida de debate; 8) Leitura de trecho original, de texto didático ou simples exposição do argumento de Kant e resposta ao problema da estratégia $7 ; 9$ ) Leitura de trecho do texto Teorias da verdade (2005), de Cláudio Costa, a fim de expor o critério pragmático de verdade como aquela que traz "vantagem prática em [se] sustentá-la", seguido de debate sobre as consequências de sua adoção; 10) Redação contendo uma proposta de intervenção que barre as consequências da prevalência de opiniões sobre fatos na democracia, utilizando os indicadores linguísticos de premissa, inferência e conclusão.

\section{Conclusão}

Como apontado na introdução, a última e definitiva versão da Base Nacional Comum Curricular está inserida na tradição já nem tão recente de dispositivos normativos brasileiros visando uma educação interdisciplinar. No caso da BNCC, esta deverá realizar-se 
por meio das competências e habilidades das diferentes áreas do conhecimento, ou então das disciplinas mais ou menos identificáveis em cada uma - o que propus aqui.

A Base é um documento vasto, quase genérico, que exigirá tempo e dedicação da parte de professores e pedagogos na tarefa de viabilizar uma educação interdisciplinar e inovadora no Brasil. Sinal disso é que as possíveis relações oferecidas pelo texto da BNCC não são explícitas, e, por isso, demandam certo esforço e criatividade por parte do professor que quiser integrar duas ou mais disciplinas.

Esse trabalho, como busquei mostrar, pode dar-se em duas frentes: por um lado, identificar nas áreas de conhecimento aquelas habilidades que mais são afins à sua disciplina e à disciplina com a qual pretende-se trabalhar conjuntamente (excetuadas, é claro, as que são explicitadas como tais, caso de Matemática e Língua Portuguesa). Por outro lado, é preciso refletir sobre que cruzamentos podem existir entre as habilidades dessas disciplinas, levando em conta seus objetos de conhecimento ou seus processos cognitivos em questão.

Com isso é possível elencar as relações interdisciplinares propriamente ditas. No caso deste artigo, elaborou-se uma lista não-exaustiva de quatro relações interdisciplinares possíveis entre Filosofia e Língua Portuguesa, tocando conteúdos como ética e epistemologia, instrumentos como análise e composição de argumentos, e aspectos socioafetivos como respeito, honestidade intelectual e abertura para o diálogo.

Relações interdisciplinares assim podem e devem gerar frutos em sequências de aulas, por isso foi apresentada uma a título de ilustração. Cabe notar, ainda assim, que a BNCC deve ser acompanhada de currículos e projetos pedagógicos para que a formulação dessas atividades seja adequada à realidade contextual dos alunos.

\section{Referências}

BRASIL. Ministério da Educação. Base nacional comum curricular: $1^{\text {a }}$ versão. Brasília, DF, 2015.

BRASIL. Ministério da Educação. Base nacional comum curricular: $2^{a}$ versão. Brasília, DF, 2016.

BRASIL. Ministério da Educação. Base nacional comum curricular: $4^{a}$ versão. Brasília, DF, 2018.

COSTA, António Paulo. A avaliação em filosofia. In: MURCHO, Desidério (Org.), Renovar o ensino de filosofia. Lisboa: Gradiva, 2003. p. 69-87.

COSTA, Cláudio. Teorias da verdade. Crítica na rede. Out. 2005. Disponível em: https:// criticanarede.com/met_tverdade.html. Acesso em: 1 de maio de 2019.

ROCHA, Ronai Pires da. A didática na disciplina de filosofia. In: CORNELLI, Gabriele; CARVALHO, Marcelo (Org.). Ensinar filosofia: volume 2. Cuiabá: Central de texto, 2013. p. 39-47. 
ROCHA, Ronai Pires da. O lugar da filosofia no currículo escolar. In: SPINELLI, Priscilla et al. (Org). Diálogos com a escola: experiências em formação continuada em filosofia na UFRGS, vol. 1. Porto Alegre: Evangraf, 2013. p. 17-28.

\section{Notas}

1 Tais como o parecer $n^{\circ} 15 / 98$ do Conselho Nacional de Educação (1998), as Orientações curriculares para o Ensino Médio (2006), o Referencial curricular do Rio Grande do Sul (2009) e mesmo o Guia de livros didáticos do PNLD (2015).

${ }^{2}$ Rocha (2013, p. 21) utiliza-se dessa imagem em contraste com um currículo de tipo mineral, em que "uma pedra [i.e.: o componente curricular)] não interage com a outra, e o crescimento ocorre por mera justaposição".

${ }^{3} \mathrm{Na}$ primeira versão $(2015$, p. 240), "a articulação dos componentes da área de Ciências Humanas no Ensino Médio demanda intensificar ações interdisciplinares e transversais". A segunda versão (2016, p. 651) adota a mesma tônica.

${ }^{4}$ Agradeço a Renan Cambraia e Eduardo Teles pelo trabalho conjunto de análise da $3^{\mathrm{a}}$ versão, do qual parto.

${ }^{5}$ BRASIL, 2018, p. 16. Trecho idêntico pode ser conferido na mesma página da terceira versão.

${ }^{6}$ São elas: Linguagens (onde está alocada a disciplina de Língua Portuguesa), Ciências da Natureza e Ciências Humanas e Sociais. Matemática consta como área à parte.

${ }^{7}$ Portanto, relações interdisciplinares que não se dão ao modo de afinidades conceituais transversais, como as que Ronai Rocha (2013), mas que ainda assim são um bom exemplo de interdisciplinaridade.

${ }^{8}$ Cada habilidade é identificada na Base por um código alfanumérico em que as duas letras ao início indicam a etapa ("EM" para Ensino Médio, por exemplo); o primeiro par de números indicam as séries em que a habilidade pode ser desenvolvida ("13" para todos os anos do Ensino Médio"; a segunda sequência de letras indica a área ou componente curricular ("LP" para Língua Portuguesa); e os números finais indicam a competência específica à qual a habilidade se relaciona, bem como sua numeração no conjunto de tais habilidades.

${ }^{9}$ Levo em conta que na seção de Ciências Humanas e Sociais da BNCC do Ensino Médio hajam de nove a dez habilidades (dentre 32) mais diretamente relacionadas com a Filosofia (EM13CHS101, 103, 105, 303, 501, 502, $503,504,603$ e 605). Logo, seria possível cumprir com todas ela ao longo dos três anos de Médio, desenvolvendo uma a cada trimestre.

\section{Correspondência}

Thiago Gruner Conceição - Rua Av. Bento Gonçalves, 9500, Prédio 43311, Bloco Al, Sala 110, Agronomia, CEP: 91.501-970, Porto Alegre, Rio Grande do Sul, Brasil.

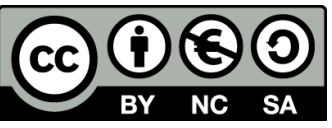

This work is licensed under a Creative Commons Attribution-NonCommercial 4.0 International (CC BY-NC 4.0) 